\title{
Indirect effects of an oil spill: reproductive failure in a population of South Polar skuas following the 'Bahia Paraiso' oil spill in Antarctica
}

\author{
Zoe A. Eppley, Margaret A. Rubega \\ Department of Ecology \& Evolutionary Biology, University of California, Irvine, California 92717, USA
}

\begin{abstract}
We report a complete reproductive failure in a population of seabirds as an indirect result of the 'Bahia Paraiso' oil spill near Palmer Station in Antarctica. Mortality among nestling South Polar skuas was highly compressed in time and was coincident with the spill. Adults were observed to forage in oil slicks and became fouled, but there was no transfer of oil to eggs or chicks. Young showed no evidence of toxicity (low growth rates or hemorrhagic gastroenteritis) and adult mortality was minimal. Instances of parental neglect increased 10 -fold after the spill and undefended chicks were attacked by neighboring skuas. We suggest that exposure to oil caused a short-term disruption of normal parental attendance behavior which exposed young to fatal intraspecific aggression. This example emphasizes that behavior and ecological interactions play major roles in determining the effects of oil on species. While these factors may be understood post hoc, correctly predicting the effects of environmental perturbations on species is a formidable task.
\end{abstract}

\section{INTRODUCTION}

Oil spills may have diverse negative impacts on organisms. Oil may exert its effects directly, through fouling or poisoning, or indirectly, through circuitous routes, such as trophic transfer or by influencing a species' predators or prey. Primary effects result from the direct exposure of organisms to oil, and include toxicity and fouling. Secondary and tertiary effects are the indirect results of primary exposure. Secondary effects include infection, reductions in longevity or fitness due to behavioral, metabolic or genetic aberrations, transfer of oil from parents to young or from prey to predator, and changes in food availability or predation pressure due to the effects of oil on the populations of other species. Tertiary effects result, in turn, from the manifestation of secondary effects.

While the primary effects of oil on organisms are well documented (see summaries in NRC 1985 and Boesch \& Rabalais 1987), only a few secondary effects have been reported. Secondary effects known from laboratory or field observations are limited to behavioral changes which increase the likelihood of mortality (microorganisms: Mitchell \& Chet 1978, Derenbach \& Gereck 1980; invertebrates: Atema et al. 1973, Jacobson \& Boylan 1973, Atema \& Stein 1974, Straughan
1976. Olla et al. 1980, Pearson et al. 1981; fish: Gardner 1975) and changes in community structure resulting from the differential mortality of prey or predator species (Beslier et al. 1980, Cabioch et al. 1980, Elmgren et al. 1980, 1983, Nellbring et al. 1980). Tertiary effects are likely to be subtle and few cases (e.g. Fry 1987) have been documented.

We report here a tertiary but profound effect of an oil spill on the reproduction of Antarctic seabirds, specifically, South Polar skuas Catharacta maccormicki. As a part of our studies on evolutionary adaptation of birds to reproduction in cold, we were monitoring the population of South Polar skuas nesting near Palmer Station when the oil spill occurred. This allowed us to compare aspects of their breeding biology both before and after the spill and we were thus in a unique position to monitor its influence on these birds. A brief preliminary note on these observations has been published previously (Eppley \& Rubega 1989).

\section{MATERIALS AND METHODS}

On 28 January 1989, the Argentine tourist/supply ship 'Bahia Paraiso' ran aground on Full Astern Reef, $2 \mathrm{~km}$ from Palmer Station, a research facility of the US 
Antarctic Program. Multiple spills occurred over the next 2 mo, releasing an estimated $1000000 \mathrm{l}$ of diesel fuel and jet fuel (Barinaga \& Lindley 1989). Large slicks were continually present for $2 \mathrm{wk}$ after the wrecking, while small slicks persisted in coastal areas into March.

In 1988-89, the South Polar skua population consisted of ca 200 breeding pairs nesting in small colonies ( 8 to 50 pairs) on several islands within $5 \mathrm{~km}$ of Palmer Station. We monitored 53 nests in 3 colonies on a daily basis from before hatching until all chicks were lost (30 December 1988 to 19 February 1989). We determined the time of hatching of each chick ( $\pm 12 \mathrm{~h}$ ) based on the development of the chick during our daily visit compared to that of known-hour-old chicks hatched in the lab. Chicks were individually identified with temporary numbered latex bands (racing pigeon counter marks). Chicks were weighed daily ( $\pm 1 \mathrm{~g}$ ) with Pesola scales. We recorded the prey types present in chick regurgitations. We noted whether adults defended their chicks or were absent. When chicks were missing from their nests we searched ca $100 \mathrm{~m}^{2}$ area looking for the chick and watched the behavior of the parents. If we found a carcass, we weighed it, checked for external injuries or lesions, and tried to determine the cause of death.

During the spill, we made a daily reconnaissance of the distribution of oil around the colonies and noted whether birds were associated with the slicks. We occasionally examined birds found in slicks from close range to determine the extent of oil fouling. We inspected adult and young skuas in the colonies of fouling during our daily nest checks. We checked other skua nesting areas to determine the generality of the mortality patterns we observed in our study sites during the spill. We did not have permits to enter the only other skua breeding area used by the population (Litchfield Island, a Specially Protected Area), and thus were unable to monitor the mixed group of brown and South Polar skuas nesting there.

We were also monitoring the population of kelp gulls Larus dominicanus adjacent to Palmer Station. By the time of the oil, spill, kelp gull young were near fledging and we checked the colonies weekly.

\section{RESULTS}

The mortality rate among nestling South Polar skuas increased sharply following the spill and continued to be high while oil was present (Table 1). By 19 February 1989, 3 wk after the 'Bahia Paraiso' started spilling oil, all South Polar skua chicks had died, both in our 53 sample nests and throughout the population. The mortality was highly compressed in time and coincided with the spill (Fig. 1)
Table 1. Catharacta maccormicki. Summary of mortality of South Polar skua chicks in 1988-89. Separate values are given for first-hatched young $(\mathrm{n}=39$, with 11 chicks hatched during the spill), which are expected to survive, and for secondhatched young $(n=12)$, which are expected to die via siblicide (Young 1963, Reid 1966, Spellerberg 1971, Proctor 1975, Pietz 1987). In 1988-89, all second-hatched young died within a few days of hatching, whether they hatched before or after the wreck. There were $28 \mathrm{~d}$ in the pre-spill monitoring period, and $21 \mathrm{~d}$ in the monitorinmg period following the spill. The death of all first-hatched young and the high daily mortality rate after the spill are unusual

\begin{tabular}{|lcc|}
\hline & Before spill & During spill \\
\hline No. of chicks & 35 & 38 \\
$\%$ Died & $37.1 \%$ & $100 \%$ \\
Daily mortality rate & $4.3 \%$ & $17.6 \%$ \\
No. of first-hatched chicks & 28 & 33 \\
$\%$ Died & $21.4 \%$ & $100 \%$ \\
No. of second-hatched chicks & 7 & 5 \\
$\%$ Died & $100 \%$ & $100 \%$ \\
\hline
\end{tabular}

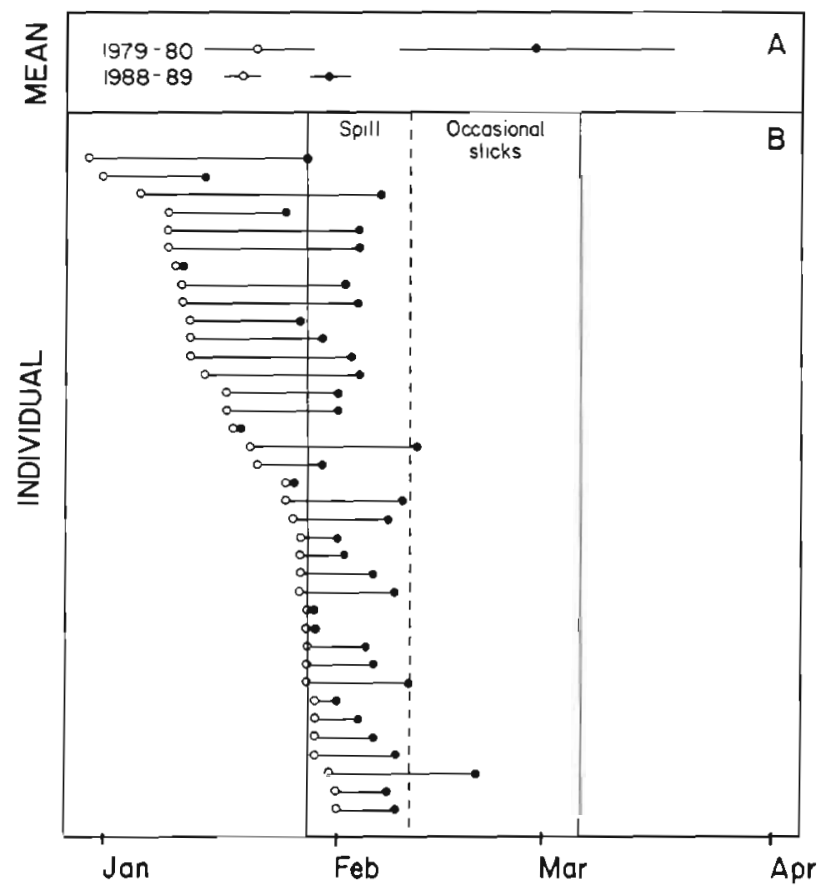

Fig. 1. (A) Catharacta maccormicki. Mean dates of hatching() and death $(\bullet$ with $95 \%$ confidence intervals for 1978-80, a year of high natural mortalıty $(0.36$ young fledged per nest; Pietz 1987. Pietz unpubl.l. and for 1988-89 10 young fledged per nest). Hatching phenology is similar (t-test for difference between mean hatching date for the $2 y_{1} t_{53}=0.45,0.9>p>$ $0.5)$ but the mean date of death for 1988-89 was significantly earlier $\left(t_{51}=2.91,0.02>p>0.001\right)$ and was significantly more compressed $\left(\mathrm{F}_{13.39}=9.67, \mathrm{p}<0.001\right)$ than for 1979-80. (B) Histories of individual first-hatched young relative to the spill. (O) Hatch date; $(\bullet$ death date. The spill occurred on January 28 and is demarked by a solid line. Large slicks were continuously present for the next $2 \mathrm{wk}$, and occasional small slicks persisted in coastal areas into March 
Although we observed adult South Polar skuas foraging in oil slicks and becoming fouled, we saw no significant oil transfer to the chicks, either through feeding or direct contact during brooding. Skuas defending their chicks were not visibly oiled. We found minor oil transfer from a brooding parent to a chick only once in 166 nest checks: this chick continued growing normally and died $11 \mathrm{~d}$ later from wounds, and thus indirect oil fouling was probably not involved in the mortality even in this instance. We found no evidence of oil transfer by feeding. Nestling skuas showed no symptoms of diesel poisoning, such as hemorrhagic gastroenteritis, and had growth rates that were not significantly lower during the spill than before (Fig. 2).

Shortly after the spill, chicks began to die or disappear from their natal territories. We found carcasses for $25 \%$ of the chicks that died during the spill: all were found on their natal territories and had wounds or were partially eaten. We found the leg and band of a missing skua chick regurgitated by a neighboring adult skua. Before the spill, all carcasses we found were uninjured (4 carcasses), and in some cases parents were still brooding them. All occurrences of wounds on chicks were due to the attacks of adult skuas, and not from sibling aggression, as all wounded chicks were from broods containing a single chick. Both before and after the spill, the second-hatched chick in each brood was driven from the nest by its older sibling within a few days of hatching (see Table 1 for comparison of mortality before and during the spill), as is common in this species (Young 1963, Reid 1966, Spellerberg 1971. Proctor 1975, Pietz 1987).

Skuas normally defend their territories continuously while they have chicks (Pietz 1986, Eppley \& Keimel unpubl.). Although neglect was rare before the spill, instances of chicks being left unattended became common during the spill (13 cases in 140 checks of broods during the spill vs 1 case in 116 checks of broods before the spill, adj. G. statistic, $\chi^{2}{ }_{1}=10.3998,0.005<p<$ $0.001)$. We observed parental lapses in territory defense coincident with chick loss in $40 \%$ of the cases of chick mortality during the spill. In 2 instances, where the natal territories were a few hundred meters from other nests, the chicks survived multiple instances of neglect and died later than chicks in denser nesting areas. Mortality of adult skuas appeared to be minimal and skua pairs were commonly observed on their territories after their chicks disappeared.

Reproductive failure was not seen any of the other species: kelp gull (pers. obs.), blue-eyed shag, Adelie penguin, southern giant petrel (Fraser pers. comm.), or the congeneric brown skua (pers. obs., Fraser pers. comm.). The adults of most species were directly exposed to oil. Adult southern giant petrels, South

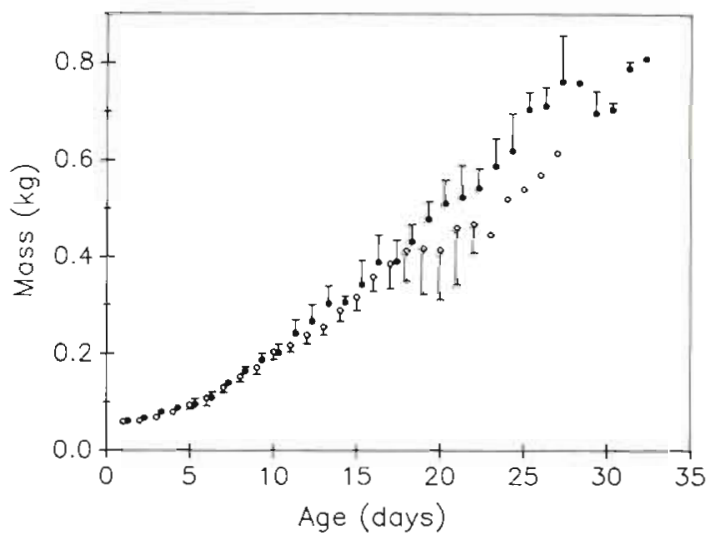

Fig. 2. Catharacta maccormicki. Growth of South Polar skua chicks in 1988-1989 (mean and 95\% confidence intervals) measured before the spill $(0)$ and during the spill $(\bullet)$. The broad overlap of the confidence intervals shows that growth rates of young after the spill were not significantly lower than before

Polar skuas, kelp gulls and Wilson's storm petrels Oceanites oceanicus were seen feeding in oil slicks (pers. obs.), whereas many blue-eyed shags and Adelie penguins became heavily oiled although they were not observed feeding in the oil slicks.

\section{DISCUSSION}

The reproductive failure of South Polar skuas after the oil spill is unprecedented in studies of this population. The skua population near Palmer Station was studied for 8 seasons between 1974 and 1989. Reproductive success in this population averages 0.8 chicks fledged per nest, with a mean clutch size of 1.9 eggs per nest. Only one other case of population-wide breeding failure is documented. This failure, in 1977-78, in which few eggs were laid and none hatched, was attributed to an energy shortage caused by ice occluding local feeding areas (Parmalee et al. 1978).

The mortality pattern among skua nestlings suggests that the mortality was a consequence of the oil spill. We have access to data on the timing of mortality for 2 breeding seasons with low productivity, 1979-80 and 1980-81 (Pietz unpubl.). One of these, 1979-80, had similar hatching phenology to 1988-89 (t-test for difference between mean hatching date for the 2 years, $\mathrm{t}_{51}=$ $0.45,0.9>p>0.5)$. Therefore, we have used the mortality pattern for $1979-80$ as a null model. In this year of natural low productivity, nestling mortality occurred throughout the nesting cycle (see Fig. 1a). In contrast, the mortality in 1988-89 was significantly earlier and more compressed (Fig. 1). All chicks died during the oil spill, regardless of age. Most deaths occurred when oil was continuously present, and the 
likelihood of adults becoming fouled was greatest. By the expected mean date of death in 1988-89 (based on the 1979-80 data), the last South Polar skua chick had been dead for over a week.

There are several potential causes of the reproductive failure of South Polar skuas in 1988-89 that can be eliminated on the basis of our observations. (1) Starvation: skua chicks might have died if parents were unable to collect and deliver enough food due to a natural or oil-related decline in prey. Although chicks that hatched during the spill lived only half as long as those that hatched before (Fig. 1b), their growth rates were not significantly lower (Fig. 2), indicating that starvation was not the cause of death. (2) Toxicity: skua chicks might have been poisoned by eating contaminated food regurgitated by their parents. But lethal or even sublethal toxicity was not evident in low chick growth rates (Miller et al. 1978). Likewise, hemorrhagic gastroenteritis, a common symptom of diesel ingestion (Croxall 1977) which occurred in sympatric blue-eyed shag chicks fed by oil-contaminated parents, was not seen in young skuas. (3) Hypothermia following fouling: skua chicks might have become oiled when brooded by oiled parents and been at risk to hypothermia when exposed. However, transfer of oil to eggs and chicks by brooding adults was observed in only one case; this chick died of wounds 11 d later. (4) Abandonment: parents killed, or those incapacitated by oil, might have abandoned their young, as was seen in blue-eyed shags (Fraser \& Culver 1989). However, skua pairs were commonly observed on their territories after their chicks died, suggesting that outright abandonment was not the cause of mortality.

We propose the following scenario to account for the reproductive failure in South Polar skuas. We hypothesize that nesting skuas became fouled while foraging in oil slicks and went to fresh water ponds to bathe and remove the light diesel coating from their plumage. This cleansing delayed their return to the nest, causing a short-term breakdown in pair coordination and nest attendance. Undefended chicks were killed by other skuas. Ultimately, all breeding pairs were affected and the entire population lost its young.

We observed that South Polar skuas commonly foraged in oil slicks when these were present and became oiled. However, we did not see oiled skuas on the colonies, or see evidence of oiled birds brooding their young. Our observations on a oiled kelp gull fledgling brought into captivity suggest that light diesel fouling may be removed by bathing over the course of $2 \mathrm{~d}$. These observations suggest that South Polar skuas became fouled by oil while foraging but cleaned themselves before returning to their nests. Bathing in freshwater ponds is a normal activity of nesting South Polar skuas at Palmer Station, occupying at least $2 \mathrm{~h}$ of their daily schedule (Pietz 1986). Because cleaning would take longer than normal shifts (Pietz 1986) away from the nest allow, the potential arose for short-term breakdown in pair coordination and lapses in nest attendance.

Skuas are known to prey on unattended eggs and young of their own species (Young 1963, Reid 1966, Proctor 1975), and continuous territory defense by parents against other skuas is crucial for the survival of their young (Pietz 1986, 1987). In 1988-89, lapses in territory defense by skua pairs were significantly more common after the wreck and usually coincided with the loss of young. Before the spill, attentive parents protected their young from predation by neighboring skuas, sometimes even preventing scavenging after chick death. Predation, although not observed before the spill, was the only observed cause of death in skua chicks during the spill. These observations suggest that during the spill, parents failed to defend their territories on occasion and these lapses permitted attacks on the young by other skuas.

This hypothesis is strongly supported by comparison of the behavior of South Polar skuas with that of other sympatric species. Reproductive failure was not seen in other species, either in noncannibalistic species which encountered oil or in the cannibalistic brown skuas. Brown skuas at Palmer Station, while generally similar to South Polar skuas, differ in a few critical aspects of their breeding biology that make them less likely to become oiled, less likely to neglect their young, and less likely to lose unattended young to predation. Unlike South Polar skuas that feed mainly at sea and are likely to encounter oil slicks, brown skuas scavenge in penguin colonies and feed on penguin eggs and young (Pietz 1987), and thus, were less likely to become oiled. Brown skuas bathe less (Pietz 1986) and thus probably spent less time away from their nests. They nest at substantially lower densities than South Polar skuas, decreasing the probability of intraspecific aggression. These minor differences in the biology of the 2 skuas resulted in reproductive failure in South Polar skuas while brown skuas apparently had normal reproductive success (censused nests contained 1 or 2 large young after the spill; pers obs., Fraser pers. comm.).

The short-term impact of the 'Bahia Paraiso' oil spill on this and other populations of seabirds at Palmer Station was unexpected and unpredictable. Instead of adverse effects on all seabird species, we saw a range of short-term responses ranging from catastrophically negative to neutral, and perhaps, to positive. Primary effects resulted in mortality in Adelie penguins and blue-eyed shags, the 2 species which neither foraged in the oil slicks nor were likely to eat contaminated prey, but which were at risk by being divers. Diving birds 
dive through the oil to escape when they encounter a slick and thus become thoroughly fouled and may then die from hypothermia, exhaustion or toxicity (Bourne 1976). These deaths provided abundant food for southern giant petrels, which are predominantly scavengers. Giant petrels fed their chicks largely on penguins after the spill and appeared to be released from the usual time constraints of distant foraging (Fraser \& Culver 1989). By satiating scavengers, which also prey on the fledglings of other seabirds, it is possible that the oil spill may have increased post-fledgling survival rates for some species, and thus may have conserved productivity

In a small spill, where the primary effects of oil are not uniformly catastrophic, secondary and tertiary effects may predominate. In the 'Bahia Paraiso' oil spill South Polar skuas suffered little mortality due to the direct effects of oil. We suggest a behavioral change occurred among South Polar skuas as a secondary effect of exposure to oil and caused them to neglect their nest attendance duties while they cleaned themselves of oil. Mortality occurred, as a tertiary effect of oil exposure, when aggressive neighbors attacked unattended young. Fouling of foraging adults, neglect of young and the loss of young to aggression was widespread and culminated in reproductive failure.

Methods of estimating the vulnerability of seabirds to oil spills currently used in oil development planning for the USA outer continental shelf use vulnerability indices to estimate the extent of mortality among seabird populations as a direct effect of oil exposure. These indices incorporate aspects of species' biology that influence the likelihood that they will contact oil and that influence the rate of recovery of their populations (e.g. King \& Sanger 1979, Ford et al. 1982, Fritts et al. 1983, Ford 1985). Indirect effects of oil on seabird populations and long-term effects are not incorporated into these models. None of these techniques, applied to the seabird populations at Palmer Station, would have predicted the differential impact of the oil spill on the 2 skua species or would have correctly ranked the direction and magnitude of the impact of the spill on the different species. The events at Palmer Station emphasize that subtle aspects of species' biology and ecological interactions may determine the magnitude and direction of the impact of oil on species. While factors that place species at risk may be understood a posteriori, it is a formidable task to predict the response of species to oil or even to recognize which aspects of the biology or ecology of species determine the consequences of oil exposure.

Acknowledgements. We thank A.F. Bennett for suggesting this paper; A.F. Bennett, G.V Lauder, E. N. Flint, W. R. Fraser, B. C. Jayne, P.J. Pietz, S. M. Reilly, R. D. Stevenson, and P. C. Wainwright for their helpful reviews; and P. J. Pietz for permitting us to use her raw data for 1979-80. We thank M. L. Tasker for his critical contributions to the field work and the people of Palmer Station for their kindness and support throughout our field season. We gratefully acknowledge the support of this work by the National Science Foundation (DPP8716005 to A.F. Bennett).

\section{LITERATURE CITED}

Atema, J., Jacobson, S., Todd, J., Boylan, D. (1973). The importance of chemical signals in stimulating behavior of marine organisms: effects of altered environmental chemistry on animal communication. In: Glass, G. E. (ed.) Bioassay techniques and environmental chemistry. Ann Arbor Scientific Publishers, Ann Arbor, Michigan, p. $177-197$

Atema, J., Stein, L. S. (1974). Effects of crude oil on the feeding behavior of the lobster Homarus americanus. Environ Pollut. 6: $77-86$

Barinaga, M., Lindley, D. (1989). Wrecked ship causes damage to Antarctic ecosystem. Nature, Lond. 337: 495

Beslier, A., Birren, J. L., Cabioch, L., Larsonneur, C., LeBorgne, L. (1980). La pollution des Baies de Morlaix et de Lannion par les hydrocarbures de l'Amoco Cadiz: repatition sur les fonds et evolution. Helgoländer Meeresunters. 33: 209-224

Boesch, D. F., Rabalais, N. (eds.) (1987). Long-term environmental effects of offshore oil and gas development. Elsevier, New York

Bourne, W. R. P. (1976). Seabirds and pollution. In: Johnston, R. (ed.) Marine pollution. Academic Press, London, p. 403-502

Cabioch, L., Dauvin, J. C., Mora Bermudez, J., Rodriguez Babio, C. (1980). Effets de la maree noire de l'Amoco Cadiz sur le benthos sublittoral du nord de la Bretagne. Helgoländer Meeresunters. 33: 192-208

Croxall, J. P. (1977). The effects of oil on seabirds. Rapp. P-v. Réun Cons. int. Mer 171. 191-195

Derenbach, J. B., Gereck, M. V (1980). Interference of petroleum hydrocarbons with the sex pheromone reaction of Fucus vesiculosus (L.). J. exp mar Biol. Ecol. 44: 61-65

Elmgren, R., Hansson, S., Larsson, U., Sundelin, B. (1980). Impact of oil on deep soft bottoms. In: Kineman, J. J., Elmgren, R., Hansson, S. (eds.) The Tsesis oil spill. National Oceanic and Atmospheric Administration Boulder, Colorado, p. 97-126

Elmgren, R., Hansson, S., Larsson, U., Sundelin, B. (1983). The Tsesis oil spill; acute and long-term impact on the benthos. Mar. Biol. 73: 51-63

Eppley, Z. A., Rubega, M. A. (1989). Indirect effects on an oil spill. Nature, Lond. 340:513

Ford, R. G. (1985). A risk analysis model for marine mammals and seabirds: a southern California Bight scenario. Final report. Contract 14-12-0001-30224. U.S. Department of the Interior, Minerals Management Service, Pacific OCS Region, Los Angeles, California

Ford, R. G., Wiens, J. A., Heinemann, D. H., Hunt, G. L. (1982). Modelling the sensitivity of colonially breeding marine birds to oil spills: Guillemots and Kittiwake populations on the Pribilof Islands, Bering Sea. J. applied Ecol. 19: 1-31

Fraser, W. R., Culver, M. E. (1989). Oil spill update and summary: surveys and sampling 28 January-4 February and 5-18 February. Report to the National Science Foundation, DPP, Polar Biology and Medicine, Washington, D.C. 
Fritts, T. H., Irvine, A. B., Jennings, R. D., Collum, L. A., Hoffman, W. McGhee, M. A. (1983). Turtles, birds, and mammals in the northern Gulf of Mexico and nearby Atlantic waters. U.S. Fish and Wildlife Service, Division of Biological Sciences, Washington, D. C. FWS/OBS-82/65

Fry, D. M. (1987). Seabird oil toxicity study. Final report. Contract 14-112-0001-29112/SBO 408(a). U.S. Department of the Interior, Minerals Management Service. Pacific OCS Region, Los Angeles, California

Gardner, G. R. (1975). Chemically induced lesion in estuarine or marine teleosts. In: Ribelin, W. E. Migaki, G. (eds.) The pathology of fishes. University of Wisconsin Press, Madison, Wisconsin, p. 657-693

Jacobson, S. M., Boylan, D. B. (1973). Effect of seawater soluble fraction of kerosene on chemotaxis in a marine snail, Nassarius obsoletus. Nature, Lond 241 213-215

King, J. G., Sanger, G. A. (1979). Oil vulnerability index for marine oriented birds. In: Bartonek, J. C., Nettleship, D. N. (eds.) Conservation of marine birds of northern North America. Wildlife Research Report 11, U.S. Fish and Wildlife Service, Washington, D. C. p. 227-239

Miller, D. S., Peakall, D. B., Kinter, W B. (1978). Ingestion of crude oil: sublethal effects in herring gull chicks. Science 199: 315-317

Mitchell, R., Chet, I. (1978). Indirect ecological effects of pollution. In: Mitchell, R. (ed.) Water pollution microbiology, Vol. 2. John Wiley \& Sons, New York, p. 177-199

National Research Council, Steering Committee for the Petroleum in the Environment Update. Board on Ocean Science and Policy, Ocean Sciences Board. Commission on Physical Sciences (1985). Oil in the sea: inputs, fates and effects. National Academy Press, Washington, D. C.

Nellbring, S., Hansson, S., Aneer, G., Weshn, L. (1980). Impact of oil on local fish fauna. In: Kineman, J. J., Elmgren, R.,

This article was presented by Dr D.C. Schneider, St. John's, Newfoundland, Canada
Hansson, S. (eds.) The Tsesis oil spill. National Oceanic and Atmospheric Administration, Boulder, Colorado, p. 193-201

Olla, B. L., Atema, J., Forward, R., Kittredge, J, Livingston, R. J., McLeese, D. W., Miller, D. C., Vernberg, W. B., Wells, P. G., Wilson, K. (1980). The role of behavior in marine pollution monitoring: behavior panel report. Rapp. P-v. Réun. Cons. int. Explor. Mer 179: 174-181

Parmalee, D. F., Bernstein, N., Neilson, D. R. (1978). Impact of unfavorable ice conditions on bird productivity at Palmer Station during the 1977-78 field season. Ant. J. U.S. 13(4): $146-147$

Pearson, W. H., Woodruff, D. L., Sugarman, P. C., Olla, B. L. (1981). Effects of oiled sediment on predation on the littleneck clam, Protothaca staminea, by the Dungeness crab, Cancer magister. Estuar. coast. Shelf Sci. 13: 445-454

Pietz, P. J. (1986). Daily activity patterns of South Polar and brown skuas near Palmer Station, Antarctica. Auk 103 $726-736$

Pietz, P. J. (1987). Feeding and nesting ecology of sympatric South Polar and brown skuas. Auk 104: 617-627

Proctor, D. C. L. (1975). The problem of chick loss in the South Polar skua Catharacta maccormicki. Ibis 117: 452-459

Reid, B. E. (1966). The growth and development of the South Polar skuas (Catharacta maccormicki). Notornis 13: 71-89

Spellerberg, I. F. (1971). Aspects of McCormick skua breeding biology. Ibis 113: 357-363

Straughan, D. (1976). Temperature effects of crude oil in the upper intertidal zone. EPA-600/2-76-127. Industrial Environmental Research Lab., Office of Research \& Development, U.S. Environmental Protection Agency, Washington, D. C

Young, E. C. (1963). The breeding behaviour of the South Polar skua Catharacta maccormicki. Ibis 105: 203-223

Manuscript first received: August 28, 1989

Revised version accepted: June 28, 1990 